\title{
The Unemployment and Participation Rates for Aggregate Human Capital
}

\author{
Alexander Monge-Naranjo, Research Officer and Economist \\ Faisal Sohail, Technical Research Associate
}

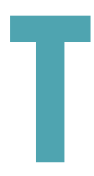

he aggregate performance of the labor market is widely followed by policymakers, such as the Federal Reserve, and the general public. The most common measure is the unemployment rate, which is the fraction of individuals in the labor force who are unemployed but actively seeking work. Recently, this measure has been center stage in the discussion of monetary policy and the prospects of the rate's future normalization. Another measure closely followed is the labor force participation rate (LFPR), which is the fraction of the working-age population actively participating in the labor market-those employed or seeking employment.

As traditionally defined, both the unemployment rate and the LFPR measure fractions of workers. However, for these measures to assess the loss in aggregate production, they must also account for the productive capacity of workers. For example, from an economic perspective, the output loss from a highly productive unemployed worker can be the same, or even larger, than the output loss from several less-productive unemployed workers. In this essay, we construct measures of the unemployment rate and LFPR that correct for the differences in the productive capacity of workers and compare them with the traditional measures followed by policymakers.

To make the correction, we assess human capital, which is the knowledge obtained through schooling and work experience. A large body of the literature has focused on accounting for human capital, and a number of important disagreements persist regarding how to measure it. Here, we adopt the most common method, the Mincer (1974) earnings function, which specifies a relationship between income, which is our proxy for human capital, $H$; years of schooling, $S$; and years of potential experience, $E$ :

$$
H=\exp \left(\beta_{0}+\beta_{1} S+\beta_{2} E+\beta_{3} E^{2}+D \cdot \text { female }\right),
$$

where female indicates gender, to allow for gender differences in earnings, as supported by the literature.
We infer years of schooling, $S$, from the educational attainment variable in the Current Population Survey (CPS) and define potential experience as a relationship between an individual's years of schooling and age. In particular, $E=A g e-S-6$, which assumes that all individuals begin school at age 6 . The approximate coefficient values $\left(\beta_{0}\right.$, $\left.\beta_{1}, \beta_{2}, \beta_{4}, D\right)=(0.66,0.13,0.05-0.00085,-0.2425)$ are from Polachek (2007) and correspond to data from the 2005 Census Bureau American Community Survey. These values are fairly standard in the literature, and our results are robust to using alternative values for the coefficients.

To assess the loss in aggregate production, unemployment and labor force participation must account for the human capital of workers.

Along with these estimates, we use seasonally unadjusted CPS data for the civilian, non-institutional population 25 years of age and older. The results are reported as 12 month moving averages. Figure 1 compares the humancapital-weighted (corrected) unemployment rate (HCUR; the blue line) with the traditional (unweighted) unemployment rate (the green line) from 1975 to 2015. Clearly, the unemployment rate for aggregate human capital (HCUR) is always lower than the unemployment rate for the number of workers. The difference between the two is shown in the right panel of Figure 1. The average gap during the period is around 0.7 percentage points, and there does not seem to be a long-term trend in this gap. The two series behave similarly and show an interesting cyclical pattern throughout the business cycle: The difference between the two increases during and after recessions. These patterns are explained by the fact that those with higher human capital are less likely to be unemployed and even less so during downturns. 


\section{Figure 1 Unemployment Rate}

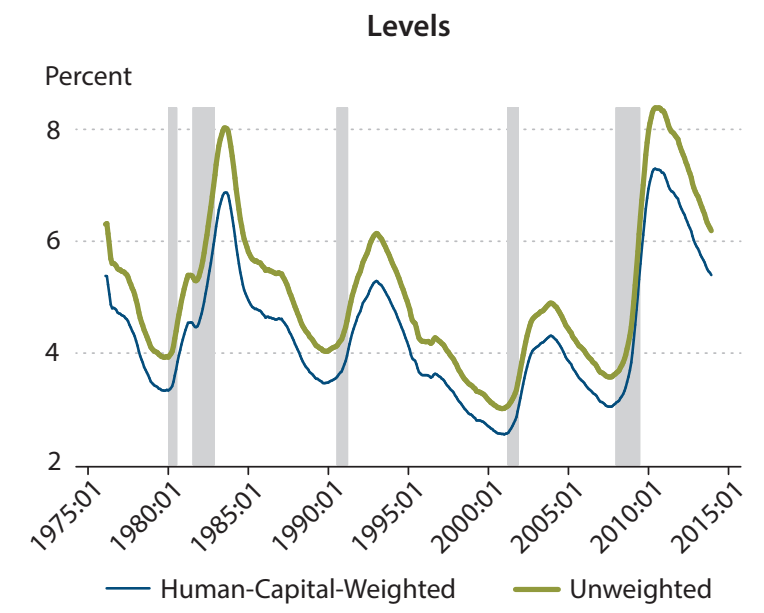

\section{Difference}

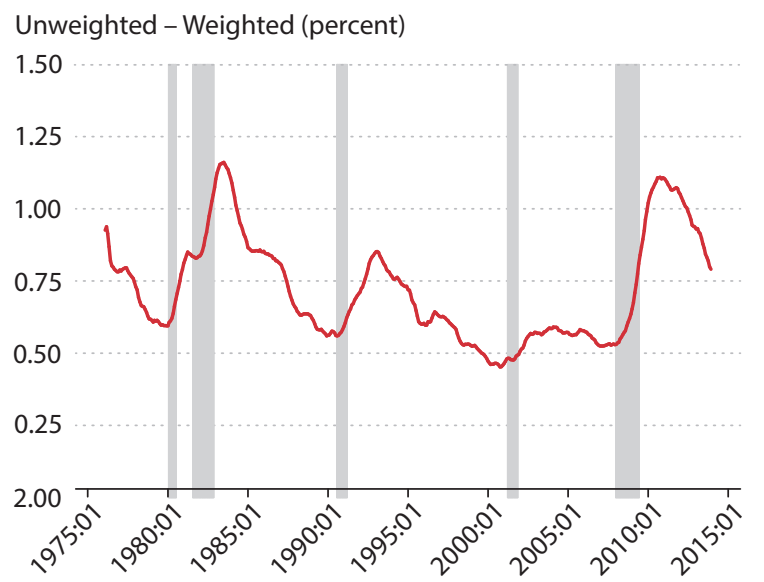

NOTE: The gray bars indicate recessions as determined by the National Bureau of Economic Research. SOURCE: CPS and authors' calculations.

\section{Figure 2 \\ Labor Force Participation Rate}

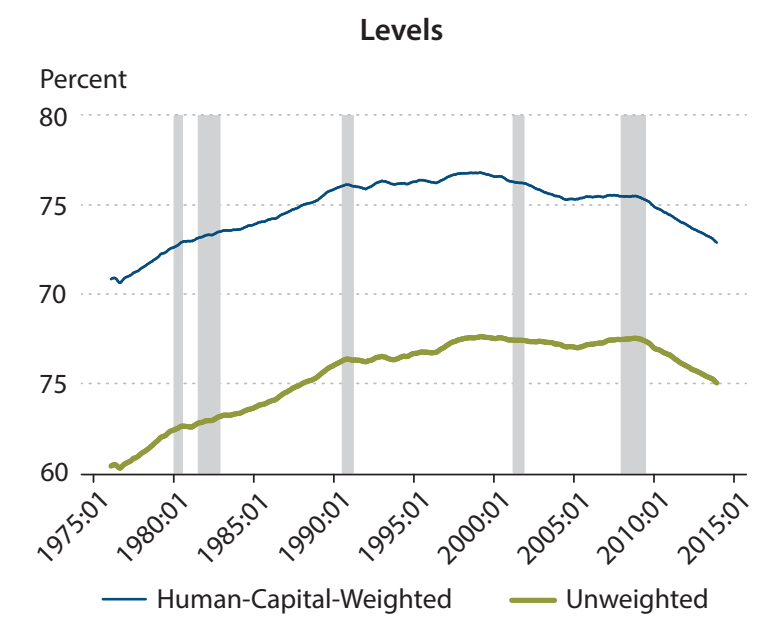

\section{Difference}

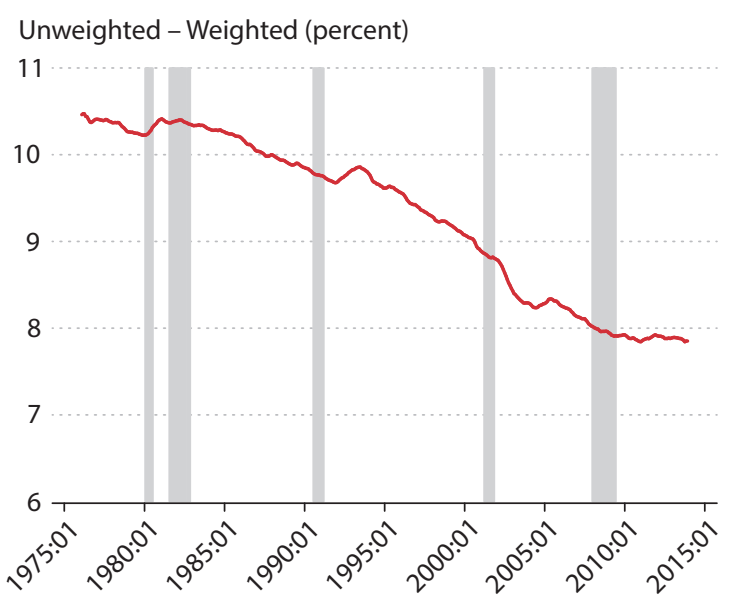

NOTE: The gray bars indicate recessions as determined by the National Bureau of Economic Research. SOURCE: CPS and authors' calculations.

Figure 2 compares the human-capital-weighted participation rate (HCPR; blue line) with the traditional (unweighted) LFPR (the green line). The LFPR remains below the HCPR, and the difference between the two series is an order of magnitude higher than between the other two series. Moreover, as clearly shown in the right panel of Figure 2, the difference between the LFPR and HCPR shows a clear trend: a decline over time from around 10.5 percentage points in early 1976 to 7.9 percentage points by the end of 2013. This declining gap is consistent with recent trends in educational attainment and labor force participation in the United States. In particular, the rise in educational attainment has increased the total stock of human capital in the population and the post-2000 decline in the LFPR has decreased the total stock of human capital in the labor force. 


\section{ECONOMIC Synopses}

In sum, the traditional measures of labor market slack tend to overestimate the fraction of the country's human capital either unemployed or not participating in the labor force. For the unemployment rate, the overestimation is procyclical. For the participation rate, it is on a downward trend, but the difference between the traditional LFPR and HCPR is more noticeable. Both overestimations are explained by the fact that a worker's unemployment and nonparticipation rates decline with an increase in his or her human capital.

\section{REFERENCES}

Polachek, Solomon W." Earnings Over the Lifecycle: The Mincer Earnings Function and Its Applications." IZA Discussion Paper No. 3181, Institute for the Study of Labor, November 2007.

Mincer, Jacob. Schooling, Experience and Earnings. New York: National Bureau of Economic Research, 1974. 